\title{
To the Results of the Detection of Genotypes of Xenobiotic Enzyme Polymorphism Genes in Pregnant Women with Fetal Loss Syndrome in Uzbekistan
}

\author{
Mavlynova NN* \\ Republican Specialized Scientific and Practical Medical Center for Obstetrics and Gynecology of the Ministry of Health of the Republic of Uz- \\ bekistan, Uzbekistan \\ *Corresponding Author: Mavlynova NN, Republican Specialized Scientific and Practical Medical Center for Obstetrics and Gynecology of \\ the Ministry of Health of the Republic of Uzbekistan, Uzbekistan.
}

Received: June 11, 2019; Published: November 05, 2019

DOI: $10.31080 /$ ASPS.2019.03.0434

Fetal loss syndrome is a multifactorial disease characterized by a universal integrated response of the female body to any ill health in the pregnant woman, the fetus and the environment, the result of the action of functionally weakened variants (alleles) of many genes against the background of adverse external and internal factors. Glutathione-S-transferase (GST) metabolizes foreign substances or controls the entry of carcinogens into cells.

The goal of our research was to establish the role of the polymorphic variants of the xenobiotic enzymes genes GSTM1 and GSTT1 GSTM1 and GSTT1 and IIe 105Val of the gene GSTP1 in the mechanism of formation and development of fetal loss syndrome.

Material and research methods

Molecular genetic studies were conducted in 114 pregnant women aged from 20 to 45 years old. Molecular genetic examination of biomaterials (DNA) was performed on the basis of the Department of Molecular Medicine and Cellular Technologies of the Research Institute of Hematology and Blood Transfusion of the Ministry of Health of the Republic of Uzbekistan. Statistical analysis of the results was carried out using the statistical software package "OpenEpi 2009, Version 2.3".

The results of molecular genetic studies in pregnant women with fetal loss syndrome (PPS) showed an increased detection rate of combined functionally defective genotypes GSTM10/0 + GSTT10/0 - 25.4\%, against the control group 4.1\% ( $\chi 2=12.4$; $\mathrm{P}$ $=0.0004 ; \mathrm{OR}=7.8 ; 95 \% \mathrm{CI} 2.146-28.65)$. Whereas, with the combined variants - the null and functional genotypes of the polymorphism of the GSTM1 and GSTT1 genes between the studied groups did not reveal statistically significant differences $(\chi 2=0.1 ; \mathrm{P}=0.3$; $\mathrm{OR}=1.4 ; 95 \%$ CI 0.697-282; $\mathrm{p}>0.05$ ). Whereas, the distribution of genotypes IIe $105 \mathrm{Val}$ of the GSTP1 xenobiotic enzyme in preg- nant women revealed a high detectability of A / G genotype polymorphism in the pregnant group compared to the control group $56.1 \%$ versus $19.4 \%$, which was 2.9 times higher than the control groups.

Thus, an analysis of the association of genic combinations of zero polymorphisms of the GSTM1 and GSTT1 genes revealed that in the group of pregnant women with fetal loss syndrome, combinations of the homozygous del / del genotype responsible for the lower level of protein product synthesis are significantly more common. The chance of developing pathology in the presence of this combination of the genotypic version of the del / del genes GSTM1 and GSTT1 increases significantly: up to 7.8 times more than other genotypes $(\chi 2=12.4 ; \mathrm{P}=0.0004 ; \mathrm{OR}=7.8 ; 95 \%$ CI 2.146-28.65). Whereas, the functionally unfavorable GSTP1 G allele 2.7 times was statistically significantly predominant in the studied chromosomes of pregnant women with PPS compared with pregnant women without PBS ( $\chi 2$ $=4.6 ; \mathrm{P}=0.03 ; \mathrm{OR}=4.5 ; 95 \% \mathrm{CI} 1.061-19.5)$.

\section{Conclusion}

Analysis of the results showed that the polymorphism variants of the GSTM10/0 + GSTT10/0 genotypes of the GSTM1 and GSTT1 genes, as well as the G / A IIe 105 Val genotypes of the GSTP1 gene are significant predictors of the risk of developing fetal loss syndrome, resulting in disorders of the detoxification process in the body in women during pregnancy.

\section{Volume 3 Issue 12 December 2019 (C) All rights are reserved by Mavlynova NN.}

